\title{
RETINOBLASTOMA IN LATE CHILDHOOD
}

\author{
Badhu B ${ }^{1}$, Sah S P ${ }^{2}$, Kumar $\mathbf{S}^{3}$, Sah R P
}

\section{ABSTRACT}

Retinoblastoma, the commonest intra-ocular tumor of childhood, is rare after the age of 5 years. We report a case of retinoblastoma in a 10 year-old boy, who presented with a fungating proptosed tender mass involving the entire left eye and the orbit. $A$ clinical diagnosis of retinoblastoma was made. Exenteration of the left orbit was done. Histopathology revealed well-differentiated retinoblastoma with the involvement of optic nerve section. CSF and bone marrow aspirates did not show any malignant cells. This paper highlights the delayed presentation of retinoblastoma in late childhood and discusses the treatment modalities of orbital retinoblastoma.

Though retinoblastoma in late childhood is uncommon, it should be considered in the differential diagnosis of leukocoria and a fungating proptosed mass.

\section{Key Words: Retinoblastoma, late childhood, fungating proptosed mass.}

\section{INTRODUCTION}

Retinoblastoma, the commonest intra-ocular tumour in childhood, is diagnosed before 5 years of age in $90 \%$ of cases. ${ }^{1,2}$ It has, however, been reported in adults ${ }^{3,4}$ even in a 74 -year-old man. ${ }^{5}$ Presentation of retinoblastoma with a fungating proptosed mass in late childhood or in adults is unusual. ${ }^{1}$ We found a case of retinoblastoma presenting as a proptosed fungating orbital mass in a 10 -year-old boy at B.P.Koirala Institute of Health Sciences, Dharan, Nepal.

\section{CASE REPORT}

A 10- year-old boy presented to the Department of Ophthalmology, B.P.Koirala Institute of Health Sciences, Dharan, Nepal with the complaint of

1. Associate Professor, Dept. of Ophthalmology, B.P. Koirala Institute of Health Sciences, Dharan, Nepal.

2. Associate Professor, Dept. of Pathology, B.P. Koirala Institute of Health Sciences, Dharan, Nepal.

3. Assistant Professor, Dept. of Ophthalmology, B.P. Koirala Institute of Health Sciences, Dharan, Nepal.

4. MD (Resident), Dept. of Ophthalmology, B.P. Koirala Institute of Health Sciences, Dharan, Nepal.

Address for correspondence : $\quad$ Dr. B. Badhu, MD (Ophthalmology), Department of Ophthalmology

B. P. Koirala Institute of Health Sciences, Dharan, Nepal.

Ph. No.: 00977-25555x3021 (R); 2008(O), Fax: 00977-25-20251

Email: aabadhu@hotmail.com 
painful rapidly growing foul smelling mass involving his left eye for three months. It was preceded by the presence of a white pupillary reflex associated with diminution of vision in the affected eye for six months. Family history was unremarkable. Past medical history was not contributory. Examination revealed a fungating proptosed tender mass of firm consistency with irregular surface and necrotic areas involving the entire left eye and orbit (Fig. 1). The right eye was

\section{Fig. 1, The clinical picture of fungating} proptosed mass in the left orbit.

normal in all aspects. The preauricular and submandibular lymph nodes were not palpable. CT scan of the orbit showed a mass involving the entire eyeball with areas of calcification as well as the involvement of optic nerve and periorbital tissue. CT of the head disclosed normal gray and white matter and no signs of intracranial masses. CSF and bone marrow aspirates did not reveal any malignant cells. A clinical diagnosis of retinoblastoma was made. The patient underwent exenteration of the left orbit under general anesthesia. Grossly the exenterated mass with oedematous and erythematous eyelids measured $7 \times 6 \times 3 \mathrm{~cm}$. The tumor was gray white in color, occupied the entire globe and extended beyond the sclera. Focal areas of necrosis and haemorrhages were also identified. Sections examined showed small round cells with hyperchromatic nuclei and scanty cytoplasm. At places, the cells were arranged in rossets and fleurettes (Fig. 2, Fig. 3). Resected

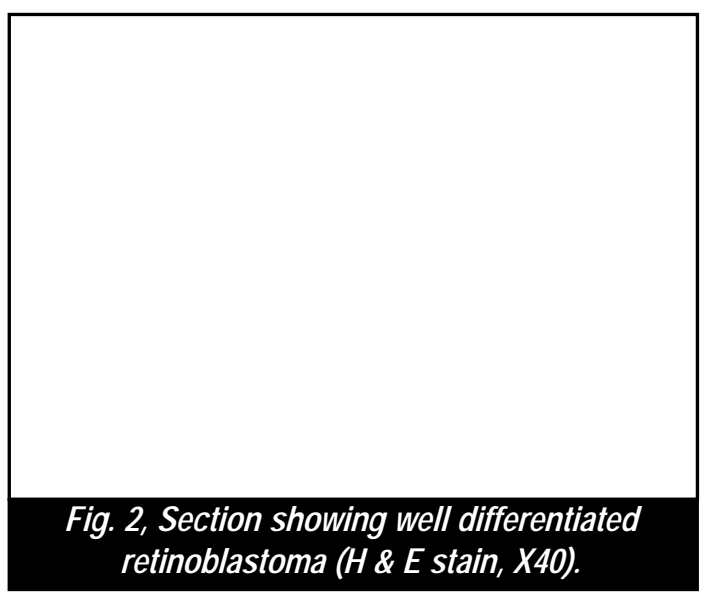

end of the optic nerve showed tumour infiltration. The diagnosis of well differentiated retinoblastoma

\section{Fig. 3, Higher magnification showing rossets and fleurettes (H \& E stain, X100).}

with involvement of the optic nerve section was offered. In the postoperative period, the orbit was allowed to granulate. The patient was referred for combined chemotherapy and radiotherapy.

\section{DISCUSSION}

The history of painless leukocoria initially for 6 months in the case presented here was significant to suspect retinoblastoma by health workers. Medical consultation, however, at that stage was not, sought for which shows poor awareness about the disease. However, what is highlighted in this 
paper is the delayed presentation of retinoblastoma with fungating mass in late childhood.

Reported modes of presentation of retinoblastoma are leukocoria, squint, hypopyon, hyphema, proptosis, secondary glaucoma, and orbital cellulitis. ${ }^{6}$ Because of its rarity in late childhood, the fungating proptosed mass or leukocoria due to retinoblastoma may be misdiagnosed. Primary health care professionals ${ }^{7}$ as well as the parents require education about the importance of ocular symptoms in pediatric patients.

Management of retinoblastoma should be guided by the objectives to save life, to retain anatomical integrity of the eye, to preserve vision, and to obtain good cosmetic results. ${ }^{7}$ If retinoblastoma could be diagnosed in its early stage, less aggressive treatment modalities like photocoagulation, cryosurgery, cobalt plaques, external beam radiation, and diathermy would be extremely useful. $^{8}$

Enucleation and exenteration are more invasive modalities, which are applied if the disease is too far advanced to salvage useful vision in the affected eye, or when other treatments have failed. ${ }^{9}$ Enucleation has to be carried out with special care not to spread tumor into the orbit during surgery and to obtain a long section of optic nerve by applying traction suture through the medial and lateral rectus insertions ${ }^{10}$ or a hemostat to the medial rectus stump. ${ }^{11}$ Lateral canthotomy has been advised in a tight orbit. ${ }^{11}$ No clamps or snares on the optic nerve stump should be used as they can leave crush artifact. ${ }^{11}$

The removal of all the orbital structures including lids, eyes, extraocular muscles, nerves and orbital fat is termed as exenteration. It is reserved for treatment of primary orbital mass or orbital recurrence of retinoblastoma. ${ }^{10}$ Orbital retinoblastoma can be treated with exenteration, local irradiation and systemic chemotherapy in combination. Studies have shown that among the patients with orbital retinoblastoma, 5\% survive when treated with exenteration alone, while $38 \%$ survive with adjuvant chemotherapy. ${ }^{12}$ The "cure" rate of retinoblastoma with exenteration and local irradiation is $30.9 \%$ vs $9 \%$ with exenteration alone. ${ }^{13}$ A long-term survivor with orbital recurrence of retinoblastoma treated with radiation and systemic chemotherapy has been reported. ${ }^{14}$ Exenteration alone may not be effective in removing the entire recurrent tumor, but in combination with radiation may affect a more complete local cure. ${ }^{15}$ The role of chemotherapy is to treat any microscopic systemic metastasis. ${ }^{15}$

\section{CONCLUSION}

1. Health education on the modes of presentation of retinoblastoma particularly leukocoria should be promoted among the population for the early detection and management of retinoblastoma.

2. Retinoblastoma is uncommon in late childhood, but its diagnosis should be considered in cases of fungating proptosed orbital mass preceded by leukocoria.

\section{REFERENCE}

1. Biswas J, Main B, Shanmugam M, et al. Retinoblastoma in adults: reports of the cases and review of literature. Survey of ophthalmology 2000; 40 (5) : 409-414.

2. Shields CL, Shields JA, Shah P, et al. Retinoblastoma in older children. Ophthalmology 1991; 98:395-9.

3. Neronova-Kotova LA. A case of retinoblastoma in an adult. Vest Oftalmol 1986; 102:75. 
4 Biswas J, Shanmugam MP, Parikh S, et al. Retindblastoma in adults: report of two cases with histopathologic correlation. Asia Pac J Ophthalmol 1996; 8:10-4.

5. Finlay JR, Byron H: Retinoblastoma in the adult: review of literature and report of a case associated with benign melanoma. Acta XIX Concilium Ophthalmologicum (New Delhi) 1962; $2: 1168-78$.

6. Mietz H, Hutton WL, Font RL. Unilateral retinoblastoma in an adult: report of a case and review of literature. Ophthalmology 1997; $104: 43-7$.

7. Goddara A G, Kingstoma J E, Hungerfordb J. Delay in diagnosis of retinoblastoma: risk factors and treatment out come. B J Ophthalmol 1999; 83:1320-1323.

8. Abramson DH. Treatment of Retinoblastoma. In : Blodi, FC, d. Contemporary Issues in Ophthalmology, Vol.2, retinoblastoma. New York: Churchill Living stone; Chapter 4, 1985: 63-93.

9. Shields, JA, Shields, CL, DePotter P. Enucleation Technique for Children with Retinoblastoma. Journal of Pediatric Ophthalmology \& Strabismus. 1992; 29, 4:213-215.
10. Abramson, DH, Ellsworth, RM. The Surgical Management of Retinoblastoma. Ophthalmic Surgery. 1980; 11, 9: 596-598.

11. Shields, JA. Misconceptions and Techniques in the Management of Retinoblastoma. Retina. 1992; 12, 4: 320-329.

12. Rootman, J, Ellsworth, RM, Hofbauer, J, and Kitchen, D. Orbital Extension of Retinoblastoma: A Clinicopathological Study. Canadian Joumal of Ophthalmology. 1978; 13:72-78.

13. Ellsworth, RM. Orbital Retinoblastoma. Transactions of the American Ophthalmologic Society. 1974; 62: 79-88.

14. Hungerford, $J$, Kingston, $J$, and Plowman, PN. Orbital Recurrence of Retinoblastoma. Ophthalmic Paediatrics and Genetics. 1987; 1: 63-68.

15. Goble, RR, McKenzie, J, Kingston, JE, Plowman, PN, Hungerford, J. Orbital Recurrence of Retinoblastoma Successfully Treated by Combined Therapy. British Journal of Ophthalmology. 1990; 74: 97-98.

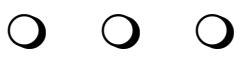

